RASĀYAN J. Chem.

Vol. 12 | No. 4 |2252 - 2259| October - December | 2019 ISSN: 0974-1496 | e-ISSN: 0976-0083 | CODEN: RJCABP

\title{
GREEN COALESCENCE AND CHARACTERIZATION OF TiO NANOPARTICLES AND EVALUATION OF ITS ANTIBIOFILM ACTIVITY
}

\author{
S.O. Dan* and S. H. Khan \\ Department of Chemistry, School of Basic Sciences, SHIATS, Allahabad, India \\ *E-mail:Ssnehadan1@gmail.com
}

\begin{abstract}
In the storyline of metal nanoparticles, green synthesis is emerging at a very fast pace. In this experimentation phenomena, nanoparticles of Titanium dioxide were coalesced using an extract solution of oscimum sanctum herba as a bioreductant. This is novel and interesting method for synthesis of TiO2 nanoparticles. The prepared titanium dioxide nanoparticles were distinguished using ultraviolet-visible spectroscopy (UV-VIS), Scanning electron microscopy (SEM), Transmission electron microscopy (TEM). The girth range of $\mathrm{TiO}_{2}$ nanoparticles was evaluated to be in the range of $90-100 \mathrm{~nm}$. Moreover, the reaction which was alkaline by behavior of the solution $(\mathrm{pH}=8)$ resulted in the increase in absorbance (at $570 \mathrm{~nm}$ and $490 \mathrm{~nm}$ ), which sparges the growth of the number of $\mathrm{TiO}_{2}$ nanoparticles in the studied solution. The microscopic technique showed that the diameter of TiO2 was in the range of 6-10 nm but with little agglomeration.Also, its Antibiofilm activity was accessed with correlation to optical densities, biofilm formation capability of microbes make their distortion tedious but fighting strategy of nanoparticles could be a revolution in antibacterial investigations $450 \mu \mathrm{g} / \mathrm{l}$ of nanoparticles from both the extracts targeted the biofilms of E.coli.
\end{abstract}

Keywords: Green Synthesis, Ocimum sanctum, X-ray Diffraction, TEM, SEM, Antibiofilm Activity

(C) RASĀYAN. All rights reserved

\section{INTRODUCTION}

Current generation majorly focuses on the minimum use of electronic devices as a major aspect than other parameters and in this, the nanotechnology plays an important role. The field and technique of nanotechnology have grabbed lots of attention due to the fact that it provides a wide application range in almost every filed of industry from textile to medicine. Very keen interest on the nanomaterial studies has been observed nowadays because the nanoparticles exhibit physicochemical and optoelectronic properties due to the bounding of electrons within their $1 \mathrm{~nm}$ dimension and this is a remarkable property of nanoparticle. The applications of nanomaterials are now extended to areas of optoelectronics, catalysis, reprography, light emitters, and single-electron transistors. ${ }^{1}$ These nanoparticles possess an increased surface area which makes them suitable for the better interaction with the pathogen when exposed hence indicating then as a suitable antimicrobial agent. Their small size enables them to enter into the bacterial cells easily and hence is capable of harming those. ${ }^{2}$ The nanoparticles are synthesized using several techniques and methods including the chemical synthesis, microbial synthesis, and green synthesis. Among them green synthesis of nanoparticles has attracted several researchers because in comparison with the chemical synthesis process they are environment-friendly as the chemical synthesis leads to the production of several toxic substances which make them improper for the biological use. As well as the chemical synthesis is cost consuming process while the green synthesis minimizes the use of chemical hence forms a cost-effective way. ${ }^{3}$ Recently titanium dioxide nanoparticles synthesized via green synthesis are widely used because of several remarkable properties of titanium dioxide. Titanium dioxide is widely used as environment-friendly and clean photo-catalyst due to its virtue of optics and chemical properties as well as its stabilization in chemical bonds and non-toxicity. ${ }^{4,5}$ Titanium dioxide is a white color solid inorganic metal oxide. It is a thermally stable, non-flammable and poorly soluble oxide and

Rasayan J. Chem., 12(4), 2252-2259(2019)

http://dx.doi.org/10.31788/RJC.2019.1245341

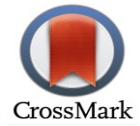


RASĀYAN J. Chem.

Vol. 12 | No. 4 |2252 - 2259| October - December | 2019

moreover it classified as the non-hazardous oxide according to the UN-GHS classification and Labeling of Chemicals. ${ }^{6}$ Along with these properties it also exhibits properties like non-wettability, hydro- fear and Band gaps with larger values. Among its various phases based on temperature the Anatase phase is assessed to have the most extraordinary chemical and physical properties. ${ }^{7}$ The titanium dioxide nanoparticles acquire the ability to react with the oxygen and hydroxyl ions which are adsorbed on the surface for obtaining oxygen and hydroxyl free radical. ${ }^{8}$ The high refractive index and high capacity to absorb UV light makes the titanium dioxide as an interesting pigment as well as an environment-friendly catalyst as well. ${ }^{9}$ Currently the metal oxides have gained lots of attention of researchers because the microbes are becoming resistant to the metal ions and titanium dioxide is found to be effective against microbes. ${ }^{10}$ Titanium dioxide is found to produce reactive oxygen species when exposed to ultraviolet radiations and they are found effective against the E. coli and Staphylococcus aureus. ${ }^{11}$ Several remarkable properties possessed by the titanium oxide nanoparticle make it essential to be used in several industries. They are used in the field of photo-catalysts, cosmetics, and pharmaceuticals. ${ }^{12}$ It also possesses varied applications in Industries including sensitization based on dye for solar cells, photocatalysis, self-cleaning, charge Lateral Charge spreading instruments, sensors who respond to chemicals, microelectronics, electrochemistry, antibacterial products, and textiles ${ }^{13,14,15,16}$ Titanium oxides are the important component of cosmetic and medicinal drugs. ${ }^{17}$ It is used to produce whiteness and opacity to paints, plastics, papers, inks, food colorants, toothpastes sunscreen lotions, paints, plastics, papers, inks, food colorants and toothpastes. ${ }^{18}$

\section{Collection of Plant Leaf Sample}

\section{EXPERIMENTAL}

Leaf sample of Ocimum sanctum was harvested from the natural habitat of Allahabad. Ocium sanctum is a very important plant due to its remarkable medicinal properties. The fresh leaves of plants were harvested for the nanoparticles synthesis from Indira Nagar, Lucknow.

\section{Preparation of Plant Extract}

Fresh leaves were collected for the extract preparation. The leaves were left to dry under shade. The leaves after drying were ground to form fine powder. Then the leaf powder was mixed with the solvent i.e., Acetone and Methanol. $10 \mathrm{gm}$ of leaf powder was mixed with $50 \mathrm{ml}$ of solvent in through Whatman filter paper. The leaf extract filtrate so obtained was stored in clean glass vessel and kept at room temperature.

\section{Synthesis of the Titanium Dioxide $\left(\mathrm{TiO}_{2}\right)$ Nanoparticles}

The leaves of oscimum sanctum sample were dried under shade for 10-15 days under dust-free condition. The dried leaves were then cut into pieces and ground into fine powder. Then 3 grams of the leaf sample was homogenized along $50 \mathrm{ml}$ of the methanol, acetone and the extraction was carried out under reflux conditions at $50^{\circ} \mathrm{C}$. After 5 hours of the extraction process the extract was obtained by filtering it through Whatman filter paper. Now for the titanium dioxide nanoparticle synthesis, an Erlenmeyer flask containing $50 \mathrm{ml}$ of leaf extract was kept at $50^{\circ} \mathrm{C}$ and to it $0.4 \mathrm{M}$ titanium tetra-isoproxide was added dropwise till yellow colored precipitation occur and this was done at continuous stirring for 3-4 hours. Then the formed nanoparticle was obtained by centrifugation of the extract prepared by adding components at 10,000 rpm for duration of 15 minutes. The obtained pellet was washed with ethanol and the obtained nanoparticle was dried, ground and calcinated at $500^{\circ} \mathrm{C}$ in muffle furnace for duration of 5 hours. Then the nanoparticle of Titanium dioxide was attained and was used for later characterization and analysis. ${ }^{19}$

\section{Characterization of the Nanoparticles}

After synthesizing the titanium dioxide nanoparticles further step was its characterization in order to gain information regarding its physical and chemical properties. The titanium dioxide nanoparticles were characterized on a different basis. The optical behavior of titanium dioxide nanoparticles was done with UV light absorption range from $200 \mathrm{~nm}-400 \mathrm{~nm}$ of wavelength. The shape and size of nanoparticles were 
RASĀYAN J. Chem.

Vol. 12 | No. 4 |2252 - 2259| October - December | 2019

analyzed through Scanning Electron Microscopy (SEM). The nanoparticles were then under given to Xray (XRD) diffraction analysis to assess the crystallinity of the nanoparticles which was performed on the $\mathrm{X}$-ray diffractometer. It was assessed through $\mathrm{Cu} \mathrm{K} \alpha$ radiation with the wavelength $1.54060 \AA$.

\section{Effect of Nanoparticles on Biofilm Formation}

The tube method described by ${ }^{20}$ was used for the assessment of the anti-biofilm activity of synthesized titanium dioxide nanoparticles. The anti-biofilm activity was assessed against the biofilm formation of Fungi-Candida albicans; Bacteria- Staphylococcus aureus, E.coli, Pseudomonas aeruginosa. For the process an individual sterile glass tube was filled with the culture media of the microbes and the tube was then loaded with $1 \mathrm{ml}$ of the overnight culture was added. Then different concentration of titanium dioxide nanoparticle was dropped to the tubes and the tubes were incubated at $37^{\circ} \mathrm{C}$ for 24 hours on the orbital shaker. After incubation the media from tubes was removed through aspiration and the tubes were washed with $5 \mathrm{ml}$ sterile water and dried for 5 minutes. Then in amount of $0.2 \%(\mathrm{w} / \mathrm{v})$ stain - crystal violet was transferred to tubes and was allowed to incubate at $37^{\circ} \mathrm{C}$ for 24 hours. Later on crystal violet solution was discarded and the tubes were allowed to air dry. After this, ethanol $95 \% \mathrm{v} / \mathrm{v}$ was transferred and absorbance was recorded at $595 \mathrm{~nm}$ using UV-Visible double beam spectrophotometer. The percentage anti-biofilm activity was calculated as:

(Optical Density of Control Broth - Optical Density of Test Broths/ Control OD) X 100

\section{Synthesis of Nanoparticle}

\section{RESULTS AND DISCUSSION}

The synthesis of nanoparticle finished when the formation of yellow-colored precipitate took place by addition of titanium tetra-isoproxide. The synthesized nanoparticle was then calcinated and its dried form was used for the other analysis and as well as for the characterization process.

\section{Characterization of Titanium Dioxide Nanoparticle}

UV- Visible Analysis of Titanium Dioxide Nanoparticles

The characterization of metal ion nanoparticle is mostly done by the UV-visible spectroscopy. The range used for metal ion nanoparticles characterization lies between $300-800 \mathrm{~nm}$. In order to ensure the amalgamation of the titanium dioxide nanoparticle in the synthesized extract as well as for the characterization of nanoparticle UV-Visible spectrophotometry was used. The spectroscopy analysis was done in the range of 200-400 $\mathrm{nm}$. The absorption maxima of nanoparticles depend upon the physical properties and in case of titanium dioxide the absorption maxima responded at $280-285 \mathrm{~nm}$ in $\mathrm{UV}-\mathrm{V}$ is spectroscopy. Therefore confirmed maxima was $280 \mathrm{~nm}$.

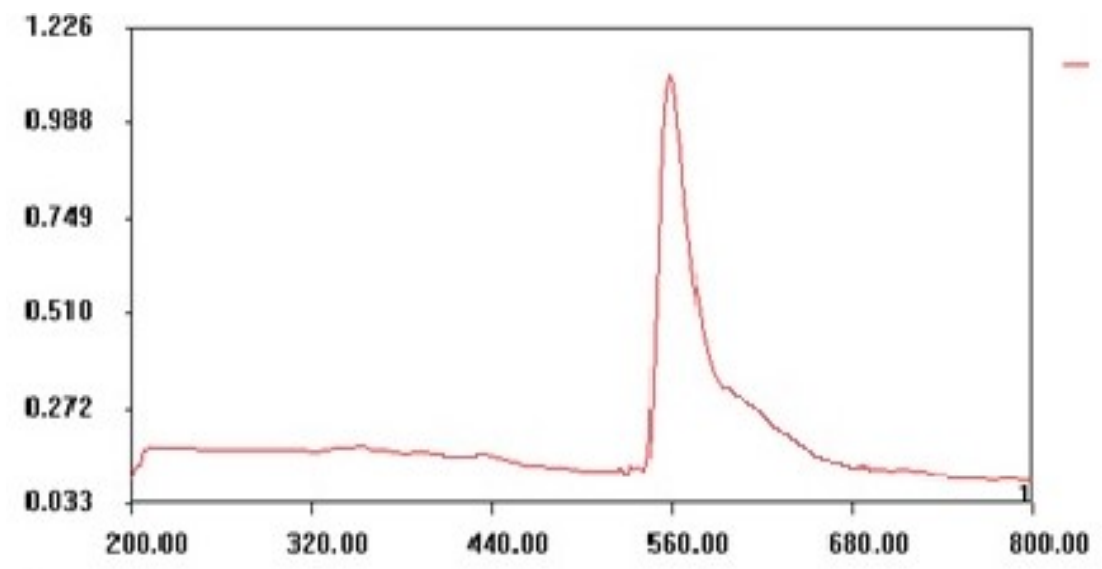

Fig.-1: The Above Graph has been Obtained For Characterization of Titanium Dioxide by Spectrophotometer, The Maximum Absorption Shown Was At $570 \mathrm{Nm}$

(Titanium Dioxide Shows Maximum Absorption Between 400 -1000 Nm) 
RASĀYAN J. Chem.

Vol. 12 | No. 4 |2252 - 2259| October - December | 2019

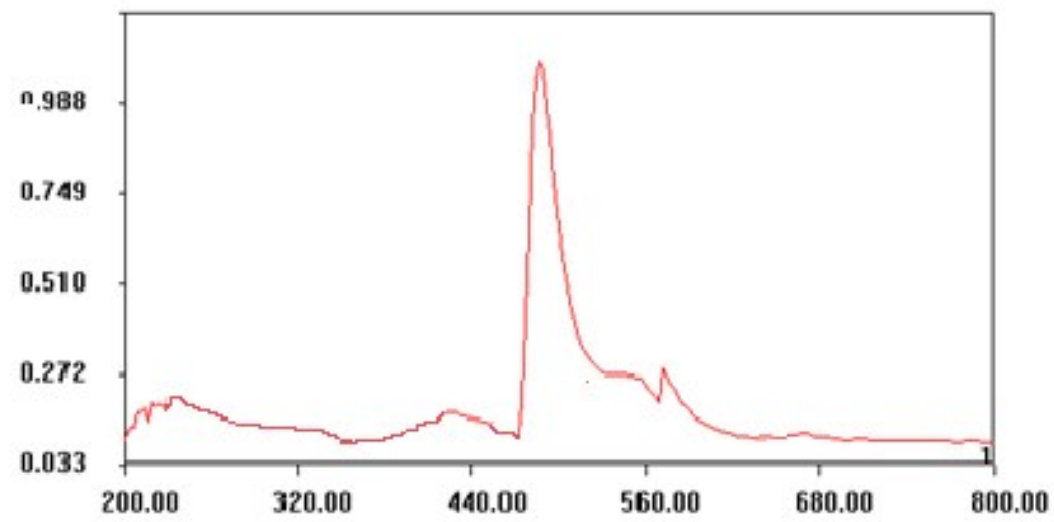

Fig.-2: Maximum Absorption was obtained At $490 \mathrm{Nm}$ for Acetone Extract of Titanium Oxide Nanoparticle

\section{SEM and TEM of Titanium Dioxide Nanoparticles}

The morphological characterization of synthesized nanoparticle was done transmission electron microscopy and the characterization of surface morphology was done by scanning electron microscopy. The SEM and TEM images were taken in different magnification range $(1 \mu \mathrm{m}-100 \mathrm{~nm})$ for SEM and $(100$ $\mathrm{nm}-500 \mathrm{~nm}$ ) for TEM. The images suggest that the synthesized nanoparticle exhibits the spherical shape and it forms clusters of particles. TEM image reveals that particles of smaller sizes aggregate into other particles to form clusters due to their possession of energy of surfaces and small dimension. The amalgamated particles have an average diameter of $\sim 6.3 \mathrm{~nm}-6.6 \mathrm{~nm}$. The TEM images show large agglomeration of the $\mathrm{TiO} 2$ particles.

\section{X-Ray Diffraction (XRD)}

The crystalline structure of the synthesized nanoparticle was analyzed through X-ray diffraction. The XRD spectra provide an insight of the crystallinity of the nanoparticles. X- Rays are able to penetrate through the crystal as they have the wavelength range of $0.01 \mathrm{~nm}$ to $100 \mathrm{~nm}$ and due to their property they provide us with the insight of the crystal structure. The X-ray diffraction motif of nanoparticle of Titanium dioxide revealed its crystalline nature at $450^{\circ} \mathrm{C}$. The orientation plane of (101) suggests the presence of anatase titanium dioxide. The straight line and sharp peaks show that the synthesized nanoparticles are crystalline in creation. The average crystal based size is determined using Scherer formula, $\mathrm{D}=\mathrm{K} \lambda / \beta \cos \theta$.
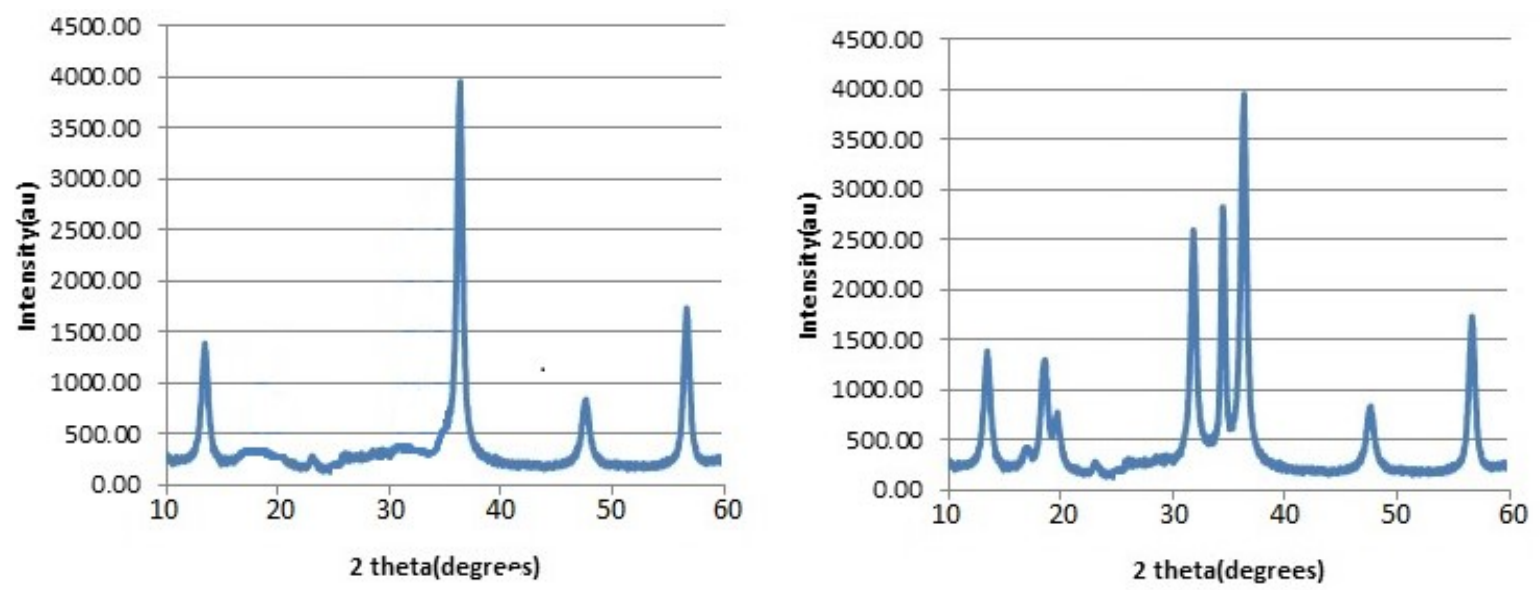

Fig.-4: XRD Graph of the Titanium Oxide Nanoparticles of Ocimum Sanctum (A) Methanolic Leaf Extract (B) Acetone Leaf Extract 
RASĀYAN J. Chem.

Vol. 12 | No. 4 |2252 - 2259| October - December | 2019

Table-1: XRD Data Analysis for Titanium Dioxide Formed From Methanolic Extract

\begin{tabular}{c|c|c|c|c|c|c|c|c}
\hline 2 theta $(\Theta)$ & $\Theta$ & $\operatorname{Cos} \Theta$ & $\operatorname{Sin} \Theta$ & FWHM & $\begin{array}{c}\text { FWHM } \\
\text { radian }\end{array}$ & $\beta \operatorname{Cos} \Theta$ & Size & dSpacing \\
\hline 12.392 & 6.1971 & 0.107949 & 0.10794 & 0.1268 & 0.12901307 & 0.1238 & 101.45 & 5.3567 \\
\hline 22.143 & 11.0716 & 0.981385 & 0.017127 & 0.1221 & 0.00013104 & 0.119827 & 103.56 & 5.2134 \\
\hline 36.214 & 18.1071 & 0.950457 & 0.016588 & 0.1217 & 0.00012406 & 0.115670 & 120.34 & 5.1215 \\
\hline 49.443 & 24.7654 & 0.908201 & 0.015856 & 0.1213 & 0.00211708 & 0.078869 & 83.09 & 3.897 \\
\hline 57.238 & 28.6198 & 0.879865 & 0.47190 & 0.1244 & 0.00217119 & 0.067319 & 76.012 & 3.9807 \\
\hline
\end{tabular}

This data tells that average size of nanoparticle obtained was $96.8904 \mathrm{~nm}$.

Table-2: XRD Data Analysis for Titanium Dioxide Formed From Acetone Extract

\begin{tabular}{c|c|c|c|c|c|c|c|c}
\hline $\begin{array}{c}2 \text { theta } \\
(\Theta)\end{array}$ & $\Theta$ & $\operatorname{Cos} \Theta$ & $\operatorname{Sin} \Theta$ & FWHM & $\begin{array}{c}\text { FWHM } \\
\text { radian }\end{array}$ & $\beta \operatorname{los} \Theta$ & Size & dSpacing \\
\hline 12.341 & 6.1075 & 0.97689 & 0.106394 & 0.106 & 0.00185 & 0.1053 & 97.324 & 7.56 \\
\hline 24.742 & 12.371 & 0.90820 & 0.418532 & 0.122 & 0.002129 & 0.1098 & 121.098 & 6.54 \\
\hline 37.142 & 18.571 & 0.79714 & 0.60379 & 0.143 & 0.0024582 & 0.1567 & 92.33 & 5.09 \\
\hline 49.421 & 24.7109 & 0.90842 & 0.75950 & 0.149 & 0.00260 & 0.1432 & 102.98 & 7.20 \\
\hline 58.212 & 29.106 & 0.87372 & 0.8500 & 0.176 & 0.00306 & 0.1765 & 87.90 & 6.2 \\
\hline
\end{tabular}

This data tells us that the average size is $98.06 \mathrm{~nm}$.

\section{Antibiofilm Activity of $\mathrm{TiO}_{2}$ Nanoparticles}

The study investigated antibiofilm activity of Titanium dioxide nanoparticle against Gram-negative, Gram-positive bacteria and a fungus was estimated by microtiter plate method. The concentrations of $\mathrm{TiO}_{2} \mathrm{NPs}$ tested against these microbes were kept $250 \mu \mathrm{g} / \mathrm{ml}, 450 \mu \mathrm{g} / \mathrm{ml}$ and $650 \mu \mathrm{g} / \mathrm{ml}$ as described in Table-3 and 4.

Table-3: Titnium Di Oxide Nanoparticle With Tulsi (Ocimum Sanctum) Acetone Extract

\begin{tabular}{|c|c|c|c|c|c|c|}
\hline \multirow[b]{2}{*}{ S.No. } & \multirow[b]{2}{*}{ Isolate } & \multirow[b]{2}{*}{ Sample } & \multicolumn{4}{|c|}{ O.D. \pm S.D. } \\
\hline & & & S.aureus & P.aeruginosa & C.albicans & $\begin{array}{l}\text { Biofilm forming strain } \\
\text { (E.coli) }\end{array}$ \\
\hline \multirow{2}{*}{1} & \multirow{2}{*}{$250 \mu \mathrm{g} / \mathrm{ml}$} & $\mathrm{NP}+\mathrm{nt}$ & $0.237 \pm 0.003$ & $0.259 \pm 0.008$ & $0.186 \pm 0.016$ & $0.256 \pm 0.005$ \\
\hline & & NP $-n t$ & $0.274 \pm 0.035$ & $0.271 \pm 0.081$ & $0.234 \pm 0.091$ & $0.283 \pm 0.087$ \\
\hline \multirow{2}{*}{2} & \multirow{2}{*}{$450 \mu \mathrm{g} / \mathrm{ml}$} & $\mathrm{NP}+\mathrm{nt}$ & $0.221 \pm 0.007$ & $0.209 \pm 0.023$ & $0.165 \pm 0.011$ & $0.142 \pm 0.004$ \\
\hline & & NP $-n t$ & $0.244 \pm 0.042$ & $0.235 \pm 0.066$ & $0.226 \pm 0.343$ & $0.214 \pm 0.087$ \\
\hline \multirow{2}{*}{3} & \multirow{2}{*}{$650 \mu \mathrm{g} / \mathrm{ml}$} & $\mathrm{NP}+\mathrm{nt}$ & $0.147 \pm 0.006$ & $0.139 \pm 0.023$ & $0.153 \pm 0.009$ & $0.156 \pm 0.006$ \\
\hline & & NP $-n t$ & $0.209 \pm 0.004$ & $0.184 \pm 0.091$ & $0.218 \pm 0.08$ & $0.214 \pm 0.009$ \\
\hline \multirow{2}{*}{4} & \multirow{2}{*}{ Positive Control } & $\mathrm{NP}+\mathrm{nt}$ & $0.119 \pm 0.007$ & $0.112 \pm 0.008$ & $0.087 \pm 0.012$ & $0.112 \pm 0.003$ \\
\hline & & NP -nt & $0.191 \pm 0.001$ & $0.164 \pm 0.007$ & $0.176 \pm 0.006$ & $0.218 \pm 0.004$ \\
\hline \multirow{2}{*}{5} & \multirow{2}{*}{$\begin{array}{c}\text { Negative } \\
\text { Control }\end{array}$} & $\mathrm{NP}+\mathrm{nt}$ & $0.083 \pm 0.012$ & $0.079 \pm 0.008$ & $0.53 \pm 0.005$ & $0.094 \pm 0.011$ \\
\hline & & NP -nt & $0.117 \pm 0.064$ & $0.114 \pm 0.094$ & $0.105 \pm 0.065$ & $0.193 \pm 0.085$ \\
\hline
\end{tabular}

$\mathrm{NP}+\mathrm{nt}=$ Nanoparticle present; NP-nt $=$ Nanoparticle absent

$\mathrm{OD}>0.24=$ positive biofilm; OD $>0.12-<0.24=$ weak biofilm; $\mathrm{OD}<0.12=$ negative biofilm

The result shows that Titanium dioxide nanoparticle generated using acetone extract of Ocimum sanctum possessed unfavorably deteriorating effect on following microorganism S.aureus, P.aeruginosa and C.albicans. Out of three test organisms, Titanium di Oxides have highest activity against P.aeruginos ${ }^{21}$ while other two organisms having a comparable activity with against S.aureus and against C.albicans at a concentration of $650 \mu \mathrm{g} / \mathrm{ml}$. An increase in antibiofilm activity was observed as the concentrations of 
RASĀYAN J. Chem.

Vol. 12 | No. 4 |2252 - 2259| October - December | 2019

Titanium di Oxide were gradually increased from $250-\mu \mathrm{g} / \mathrm{ml}$ upto $650 \mu \mathrm{g} / \mathrm{ml}$. A slight variation was seen in case of Titanium dioxide synthesized from methanolic extract of Ocimum sanctum. In this case, highest activity was observed against fungus C.albicans, followed by activity against S.aureus ${ }^{22}$ than P.aeruginosa. All these activities at titer of $650 \mu \mathrm{g} / \mathrm{ml}$ of NPs had shown that as the concentration increases, there is increase in inhibiting effect. Therefore, these NPs were found to be effective at higher concentration. The results were deduced in reference to positive and negative controls and also a biofilm-forming strain of E.coli. ${ }^{23}$ Thus these Titanium di Oxide nanoparticles said to have capability in preventing formation of these biofilms as when compared to negative control. ${ }^{24}$ This study results demonstrated that effective doses of Titanium di Oxide, against both the spectrum of Gram's staining and fungus are significant. Their effectiveness was observed between range of $250 \mu \mathrm{g} / \mathrm{ml}-650 \mu \mathrm{g} / \mathrm{ml}$ and their minimum effective dosage was confined to $450 \mu \mathrm{g} / \mathrm{ml}^{25}$

Table-4: Titanium Oxide Nanoparticle With Tulsi (Ocimum Sanctum) Methanolic Extract

\begin{tabular}{|c|c|c|c|c|c|c|}
\hline \multirow[b]{2}{*}{ S.No. } & \multirow[b]{2}{*}{ Isolate } & & \multicolumn{4}{|c|}{ O.D. \pm S.D. } \\
\hline & & & S.aureus & P.aeruginosa & C.albicans & $\begin{array}{l}\text { Biofilm forming } \\
\text { strain (E.coli) }\end{array}$ \\
\hline \multirow{2}{*}{1} & \multirow{2}{*}{$250 \mu \mathrm{g} / \mathrm{ml}$} & $\mathrm{NP}+\mathrm{nt}$ & $0.229 \pm 0.017$ & $0.245 \pm 0.035$ & $0.172 \pm 0.007$ & $0.216 \pm 0.033$ \\
\hline & & $\mathrm{NP}-\mathrm{nt}$ & $0.269 \pm 0.167$ & $0.213 \pm 0.047$ & $0.241 \pm 0.163$ & $0.202 \pm 0.074$ \\
\hline \multirow{2}{*}{2} & \multirow{2}{*}{$450 \mu \mathrm{g} / \mathrm{ml}$} & $\mathrm{NP}+\mathrm{nt}$ & $0.207 \pm 0.009$ & $0.193 \pm 0.009$ & $0.165 \pm 0.010$ & $0.163 \pm 0.006$ \\
\hline & & NP $-n t$ & $0.242 \pm 0.054$ & $0.216 \pm 0.067$ & $0.202 \pm 0.048$ & $0.235 \pm 0.048$ \\
\hline \multirow{2}{*}{3} & \multirow{2}{*}{$650 \mu \mathrm{g} / \mathrm{ml}$} & $\mathrm{NP}+\mathrm{nt}$ & $0.158 \pm 0.009$ & $0.175 \pm 0.004$ & $0.132 \pm 0.005$ & $0.174 \pm 0.009$ \\
\hline & & $\mathrm{NP}-\mathrm{nt}$ & $0.213 \pm 0.004$ & $0.183 \pm 0.008$ & $0.214 \pm 0.010$ & $0.215 \pm 0.006$ \\
\hline \multirow{2}{*}{4} & \multirow{2}{*}{ Positive Control } & $\mathrm{NP}+\mathrm{nt}$ & $0.109 \pm 0.006$ & $0.117 \pm 0.008$ & $0.106 \pm 0.008$ & $0.108 \pm 0.004$ \\
\hline & & $\mathrm{NP}-\mathrm{nt}$ & $0.219 \pm 0.011$ & $0.165 \pm 0.007$ & $0.154 \pm 0.005$ & $0.216 \pm 0.010$ \\
\hline \multirow{2}{*}{5} & \multirow{2}{*}{ Negative Control } & $\mathrm{NP}+\mathrm{nt}$ & $0.084 \pm 0.004$ & $0.096 \pm 0.012$ & $0.084 \pm 0.007$ & $0.072 \pm 0.009$ \\
\hline & & $\mathrm{NP}-\mathrm{nt}$ & $0.161 \pm 0.057$ & $0.144 \pm 0.094$ & $0.144 \pm 0.067$ & $0.166 \pm 0.076$ \\
\hline
\end{tabular}

$\mathrm{NP}+\mathrm{nt}=$ Nanoparticle present; NP-nt $=$ Nanoparticle absent

$\mathrm{OD}>0.24$ = positive biofilm; $\mathrm{OD}>0.12-<0.24$ = weak biofilm; $\mathrm{OD}<0.12=$ negative biofilm

\section{Characterization through Scanning Electron Microscopy}

The grain size, shape and surface properties like morphology were investigated by the Scanning Electronic Microscopy the images were observed by the magnification of near about 10 micrometers. The microscopy stated that the size of the particles were between 1 to 100 nanometers. The size of nanoparticle formed by the oscimum sanctum extract of methanol showed the grain size radii as in the range of 6-8 $\mathrm{nm}$ while the grain size acetone extract-based nanoparticle was found to $10-12 \mathrm{~nm}$. Therefore by putting all the above facts in consideration one could possibly give inference that nanoparticles formed by acetone extract were bigger in size. The magnification was analyzed about 5000 to $10,000{ }^{26}$

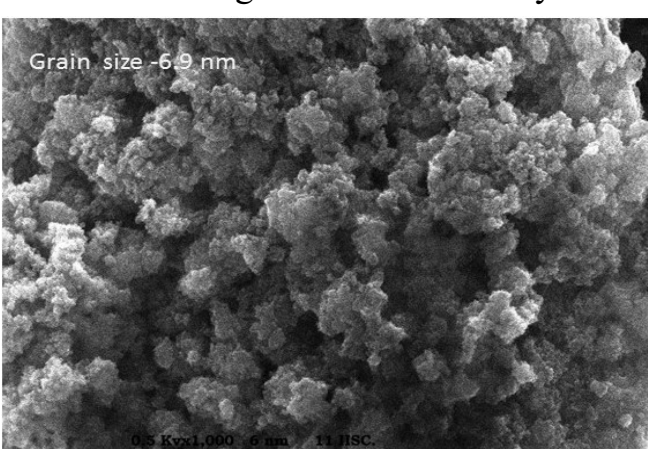

Fig.-5: Scanning Electron Microscopy of Methanol Extract Based Extract $(6 \mathrm{Nm})$

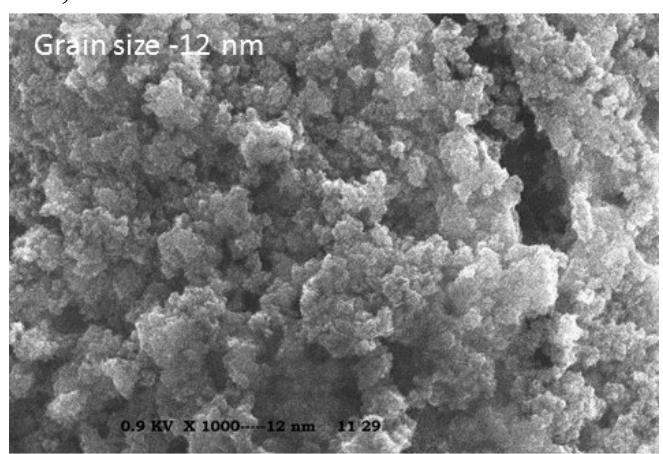

Fig.-6: Scanning Electron Microscopy of Acetone Based Extract (12 Nm) 
RASĀYAN J. Chem.

Vol. 12 | No. 4 |2252 - 2259| October - December | 2019

\section{Transmission Electron Microscopy}

The morphology and structure arrangement were observed by TEM. . It shows that $\mathrm{TiO}_{2}$ nanoparticles were found to have crystalline nature also the $d$ spacing found was quiet related to the XRD results that means near about $6 \mathrm{~nm}$ for acetone extract $8 \mathrm{~nm}$ for methanolic extract.
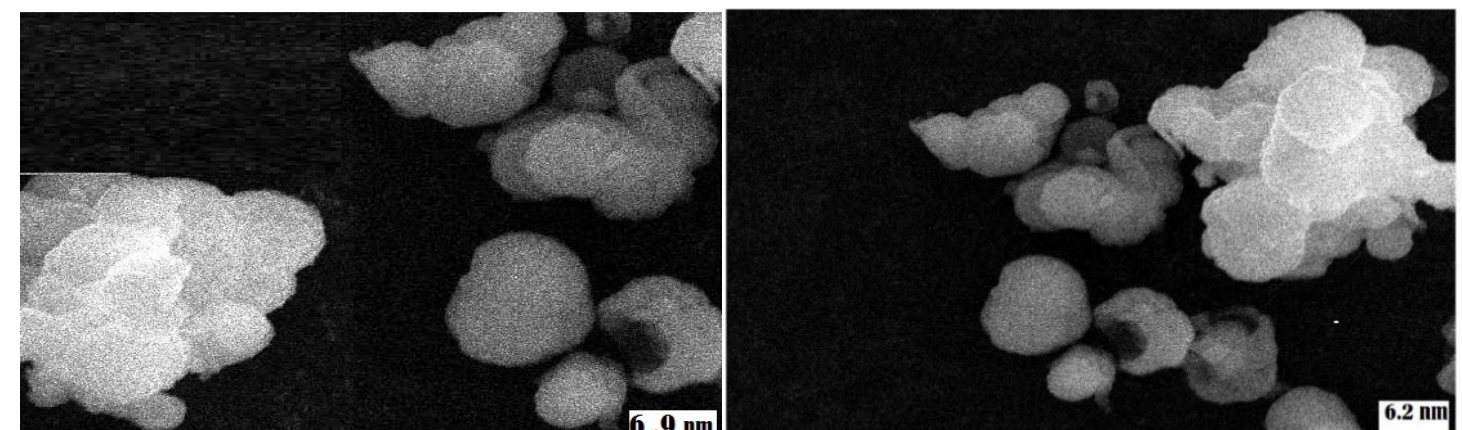

Fig.-7: Transmission Electron Microscopy of Titanium Nanoparticles Produced From The Extracts of Methanol

And Acetone Both Gave Approximately Similar Radii And The The Structure Formed Appeared To Be Spherical.

\section{Discussion}

The Size Ranged From 6-7nm.

In this research halcyon coalescence of $\mathrm{TiO}_{2}$ nanoparticles was performed using a method of green synthesis method the plant chosen for this phenomena was oscimum sanctum. ${ }^{27}$ The crystalline on average was gauge to be $96.08 \mathrm{~nm}$ calculated by Scherer's formula ${ }^{28}$, From XRD analysis average crystallite size of the sample was obtained $96.08 \mathrm{~nm} .^{29}$ It is observed that Tetragonal structure was formed. The average particle size was estimated 6-10 nm from particle size analyzer. The tetragonal irregular particles structure was observed in SEM image. ${ }^{30}$ TEM image infers that morphology of the nanoparticles showing crystalline nature. The study aimed to synthesize $\mathrm{TiO}_{2}$ nanoparticles using plant extract of Ocimum sanctum and analyze their effectiveness in prevention of biofilm formation by a gram-positive-S.aureus ${ }^{31}$, a gramnegative P.aeruginosa $a^{32}$ and a fungus (C.albicans). Titanium di Oxide nanoparticles said to have capability in preventing formation of these biofilms as when compared to negative control. This study results demonstrated that effective doses of Titanium di Oxide, against both Gram-positive Gram-negative bacteria and fungus are significant. Their effectiveness was observed between range of $250 \mu \mathrm{g} / \mathrm{ml}-650 \mu \mathrm{g} / \mathrm{ml}$ and their minimum effective dosage was found to be $450 \mu \mathrm{g} / \mathrm{ml}$ against strong biofilms of E.coli while other microbes didn't such required this amount they showed effectiveness at $250 \mu \mathrm{g} / \mathrm{ml}$ for both the extracts whether it was acetone or methanolic extract. ${ }^{33}$

\section{CONCLUSION}

In conclusion, as the technological benefits of nanotechnology begin to rapidly move from laboratory to large-scale industrial production, the nanomaterials are used in all biomedical applications. The present novel method is capable of reducing Titanium Isopropoxide to TiO2 NPs using oscimum sanctum leaf with ethanolic and acetone extract. The synthesized $\mathrm{TiO} 2$ nanoparticles were characterized by using XRD, SEM and TEM and its activity against biofilm-forming isolates S.aureus, P.aeruginosa Candida albicans and E.coli. Green approach has recent advances over chemical methods for plants being available in abundance and ecofriendly.

\section{ACKNOWLEDGMENT}

This study was bolstered up by the Department of Chemistry, SHUATS, and Allahabad (U.P.). I would like to extend my gratitude to my guide for her immense support in this work and important suggestions in improvement of this paper.

\section{REFERENCES}

1. M. Sastry, A Ahmad, M.I. Khan, R. Kumar, Curr. Sci., 85(2), 162(2011).

2. V. Kandi , Sepi Kandi, H 37: e2015020(2015), DOI:10.4178/epih/e2015020

3. V. Parashar, R Parashar, B. Sharma, and A.C. Pandey, Dig. J. Nanomater. Biosci., 49(1), 45(2009), DOI: 10.1 .1 .473 .7183 .

4. M. R. Hoffmann, S.T. Martin, W. Y. Choi, D.W. Bahnemann, Chem. Rev., 95, 69(1995), DOI: 10.1021/cr00033a004 
RASĀYAN J. Chem.

Vol. 12 | No. 4 |2252 - 2259| October - December | 2019

5. A. Fujishima, T. N. Rao, D. A.Truk, J. Photochem. Photobiol. C: Photochem., 1, 1(2007), DOI: $10.1016 / \mathrm{S} 1389$

6. M. Aadarsh, Int. J. Mech. Eng. \& Rob. Res., 3(3), 7(2003), DOI: 10.18178/ijmerr .

7. M. Rajneesh, D. Jana and H. Jaromir, Nanoscale Research Letters, 8(1), 4 pages(2013), DOI: 10.1186/1556-276x-13-503.

8. G. Rajakumar, A.A. Rahuman, B. Priyamvada, V.G. Khanna, D.K. Kumar, P. J. Sujin, Mater .Lett., 68, 115(2012), DOI: 10.1016/j.matlet.2011.10.038.

9. J. Zhao and X.Yang, Build. Environ., 38, 645(2003), DOI:10.1016/SO360-1323 (02) OO212-3

10. A. M. Allahverdiyev, E. S. Abamor, M. Bagirova, M. Rafailovich, Fut. Microbiol., 8, 933(2011), DOI: 10.2217/FMB.11.78.

11. H. Kong, J. Song, and J. Jang, Environ. Sci. Technol., 44(14), 5672(2011), DOI: 10.1021/es1010779 .

12. A.V. Kirthi , A.A. Rahuman, G. Rajakumar, S. Marimuthu , T. Santhoshkumar, C. Jayaseelan, Mater. Lett., 65(17), 2745(2011), DOI:10.1016/S1995-7645(14)60171-1.

13. B. Saowaluk, S. Weerawan. And S. Lek, Advanced Materials Research, 214, 197(2011), DOI: 10.4028.scientific.net/AMR.214.197

14. V. Dejan, V. Nika, U. Lavrencic Stangar, M. Kete, K. Zagar and M. Ceh, International Journal of Photoenergy, ID 329796, 10 pages (2012).

15. I. Dar. M., A. K Chandiran, M Gratzel, K Mohammad, J. Mater. Chem. A, 2, 1662(2014), DOI: 10.1039/C3TA14130F.

16. B. Trouiller, R. Reliene, A. Westbrook, P. Solaimani, R. H. Schiest, Cancer Res., 69, 8784(2009) DOI: 10.1158/0008-5472.CAN-09-2496.

17. C. Gelis, S. Girard, A. Mavon, M. Delverdier, N. Pailous, P. Vicendo, Photodermatol Photoimmunol Photomed, 19, 242(2003), DOI:10.4314/tjpr.v16i12.2

18. M. Sundrarajan, S. Gowri, Chalcogenide Letters, 8, (2011).

19. A.J. Abdulhassan, Effect of Silver and Titanium Nanoparticles Synthesized by Lactobacillus as Antimicrobial ,Antioxidant and Some Physiological Parameters, Master Thesis, University of Kufa, Faculty of Science-Iraq, pp. 86-93(2006).

20. F. Lavaee, K. Faez, N. Hadi, F. Modaresi, Am. J. Dent., 29(6), 315(2016).

21. Y. Lumin, S. Fei, X. Chen, J. Ni , L. Yu ,S. Dongdong, and T. Xue, PMCID, PMC6195112(2018), DOI: $10.7717 /$ peerj. 5711.

22. W. Yuan, J. Ji , J. Fu, J. Shen, A. J. Biomed. Mater. Res. B Appl. Biomater., 85(2), 556(2008), DOI: 10.5301/ijao.5000050.

23. Hani A. Alhadrami and Faten Al-Hazmi, Journal of Bioelectronics and Nanotechnology, 2(1), 5(2017).

24. S. Sundrarajan, Gowri, Chalcogenide Letters, 8(8), 447(2011).

25. K. Khairan Zahraturriaz and Z. Jalil, Rasayan J. Chem., 12(1), 50(2019), DOI: 10.31788/RJC.2019.1214073.

26. P. Vivek, J. Preeti, International Research Journal of Engineering and Technology, 4, 3(2011).

27. A. Jesline, Neetu, P. John, P. M. Narayanan, C. Vani, S. Murugan, Applied NanoScience, 5(2), 157(2019), DOI:10.1007/s13204-014-0301-X.

28. T. Kamakshi, G.S. Sunita, H. Erothu and T. P. Rao, Rasayan J. Chem., 11(3), 1113(2018), DOI: 10.31788/RJC.2018.1134003.

29. S. Zeljko, B. Sonja, Maja Vitorovic Todorovic, Natasa Pajic, Aleksandar Samolov and Dusan Rajic, Scientific Technical Review, 61(3-4), 63 (2011).

30. Nawfal Hussein Aldujaili, Mohammed Mohsen Alrufa, Fatima H. Sahib, J. Pharm. Sci. \& Res., 9(7), 1220(2017).

31. H. Zhang, G. Chen, Environ. Sci. Techno., 43(8), 2905(2009), DOI:10.1021/es803450f

32. V. Varahalarao, B. Mohan and M.Nagalakshmi Devamma, Rasayan J. Chem., 7(3), 219(2018).

33. K.L. La Plante, S.A.Sarkisian, S. Woodmansee, D.C Rowley., and N.P. Seeram, Phytotherapy Research, 26(9), 1371(2012), DOI:10.1002/ptr.4592.

[RJC-5341/2019] 